\title{
Propriedades mecânicas do talo de carnaúba (Copernicia prunifera) obtidas através de ensaios de tração
}

\author{
Edgley Alves de Oliveira Paula ${ }^{1 *}$, Claudia Yanara Meira da $\operatorname{Costa}^{1}$, Lucas Emanuel Sales da Silva ${ }^{1}$, Filipi \\ Marques de Souza ${ }^{2}$, Rafael Rodolfo de Melo ${ }^{1}$
}

\begin{abstract}
RESUMO: A carnaúba (Corpernicia prunifera) é uma espécie de planta nativa do Nordeste brasileiro, de importância reconhecida e que teve o seu auge no século XIX através da extração da cera. Entre as muitas partes importantes dessa espécie, o talo é uma que se destaca devido as suas versáteis utilizações, como em coberturas de casas, artesanato, brinquedos e móveis. Nesse âmbito, a presente pesquisa teve como objetivo caracterizar as propriedades mecânicas do talo da carnaúba, a partir de ensaios de tração. Para isso, coletou-se os talos em carnaubeiras na zona rural do município de Governador Dix-Sept Rosado e, em seguida, transportou-se os mesmo para o laboratório onde realizou-se as etapas de limpeza e fabricação dos corpos de prova. Os ensaios de tração foram realizados utilizando-se uma Máquina de Ensaios Universal, e os dados obtidos foram analisados para a obtenção dos resultados. A partir dos resultados, caracterizou-se as propriedades mecânicas médias de tensão máxima, deformação normal e módulo de elasticidade dos talos. $\mathrm{O}$ talo de carnaúba apresentou resistência média à tração de 19,703 MPa e deformação normal de 0,0549 (mm.mm $\left.{ }^{-1}\right)$.
\end{abstract}

Palavras-chave: material natural, fabricação, resistência mecânica, aplicações.

\section{Mechanical Properties of Carnaúba stalk (Copernicia prunifera) obtained through Tensile Testing}

\begin{abstract}
The carnaúba (Corpernicia prunifera) is a species of native plant to Brazilian Northeast, of recognized importance and which had its peak in the 19th century through wax extraction. Among the many important parts of this species, the stalk is one that stands out due to its flexibles uses, such as roofs, handicraft, toys and furniture. In this context, the present research aimed to characterize the mechanical properties of the carnauba stalk, from tensile tests. For this, the stalks were collected in carnaubeiras in the rural area of the municipality of Governador Dix-Sept Rosado and then transported them to the laboratory where the cleaning and manufacturing of the specimens were carried out. The tensile tests were performed using a Universal Test Machine, and the data obtained were analyzed to obtain the results. From the results, the mean mechanical properties of maximum stress, normal strain and modulus of elasticity of the stalks were characterized. The carnauba stalk showed mean tensile strength of 19,703 MPa and normal strain of 0,0549 $\left(\mathrm{mm} \cdot \mathrm{mm}^{-1}\right)$. Keywords: natural material, manufacturing, mechanical strength, applications.
\end{abstract}

\section{INTRODUÇÃO}

A carnaúba (Corpernicia prunifera) ocupava vastas extensões da área de várzea do Vale do Açu, e começou a ganhar destaque já no início do século XVIII, na consolidação da ocupação portuguesa no Vale, com o seu uso em utensílios caseiros, chapéus, etc. Mas, foi no século XIX, através da extração de sua cera, que a carnaúba começou a ser exportada e assim conquistou o comércio nacional $\mathrm{e}$ internacional, iniciando o chamado Ciclo da Carnaúba (ALBANO, SÁ, 2009).

A espécie Copernicia prunifera (Mill.) H. E. Moore, popularmente conhecida como carnaúba ou carnaubeira, tem uma grande importância econômica, social e ambiental, e no âmbito econômico, apresenta múltiplos usos, destacando-se na extração do pó

1 Universidade Federal Rural do Semi-Árido

2 Universidade Federal do Oeste da Bahia

* Email: edgley.22@hotmail.com cerífero e aproveitamento das folhas no artesanato. No seu domínio social, destaca-se a geração de ocupação no meio rural, já no ambiental colabora com o equilíbrio dos ecossistemas nos quais se insere (COSTA, GOMES, 2016).

A carnaúba é uma espécie nativa de reconhecida importância no Nordeste brasileiro, pelos aspectos econômico, social, cultural e ambiental, sobretudo nos estados do Piauí, Ceará, Maranhão e Rio Grande do Norte. Componentes das matas ciliares nordestinas, esta espécie cumpre funções fundamentais ao equilíbrio ecológico regional, em especial na conservação dos solos e proteção dos rios contra processos de erosão e assoreamento. Nos aspectos econômicos e sociais, a carnaúba também é 
muito importante na vida das populações indígenas e sertanejas, pois possui múltiplas utilidades, onde as raízes tem aplicações medicinais, o tronco é utilizado em construções, o palmito e os frutos servem como alimentação para animais de criação, e as palhas podem ser utilizadas para confecção de utensílios domésticos, adubação do solo, além de produzirem uma cera detentora de qualidades físico-químicas excepcionais (CERQUEIRA, GOMES, 2017; D’ALVA, 2004).

Assim como o tronco, as folhas e o fruto extraídos da carnaúba (Copernicia prunifera), o talo também apresenta inúmeras aplicações importantes, que vão desde da produção de artesanatos, brinquedos, móveis e objetos, até a coberturas de casas e apenderes. Dessa forma, o presente estudo teve como objetivo caracterizar as propriedades mecânicas do talo extraído da carnaúba, utilizando-se de ensaio de tração axial.

\section{MATERIAL E MÉTODOS}

Para o desenvolvimento do trabalho, realizou-se as coletas dos talos em estado seco, em carnaubeiras de uma propriedade no sítio Bomburral, zona rural do município de Governador Dix-Sept Rosado, localizado no interior do Estado do Rio Grande do Norte. Os talos coletados foram transportados para o Laboratório de Engenharia Mecânica da Universidade Federal Rural do Semi-Árido (UFERSA), onde passaram por processos tratamento de limpeza e corte dos espinhos.

Para a fabricação dos corpos de prova do ensaio de tração, realizou-se uma adaptação da norma de ensaios de tração axial em madeira da Comissão Panamericana de Normas Técnicas (COPANT 30:1 015), em virtude de os talos não possuírem as dimensões estabelecidas pela normativa. Para a adaptação, produziu-se um gabarito para marcação dos talos e, em seguida, realizou-se a marcação das medidas; com a utilização de estilete, cortou-se manualmente 12 talos no sentido paralelo à fibra, resultando em 12 corpos de prova nas dimensões de 30 × 200 × 20 mm, com uma área de seção transversal de $27 \mathrm{~mm}^{2}$ na região central (Figura 1).

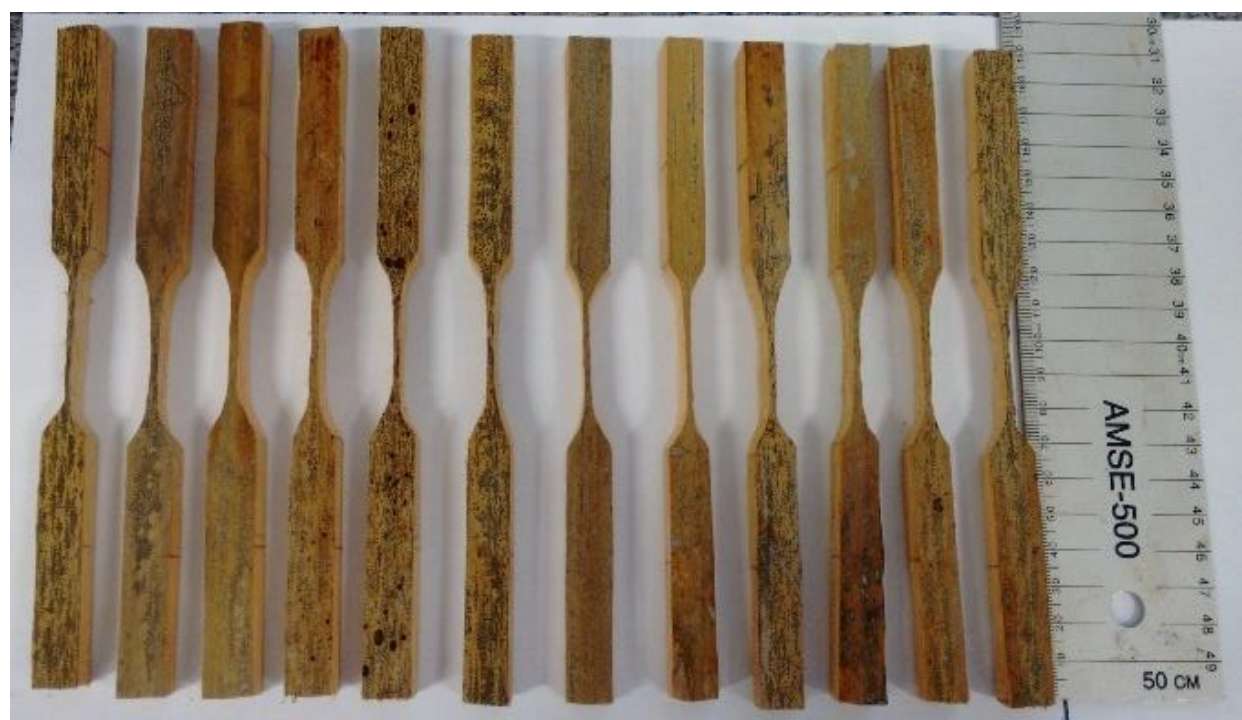

Figura 1 - Corpos de prova produzidos a partir do talo da carnaúba (Copernicia prunifera).

Com utilização de uma Máquina de Ensaio Universal, realizou-se os ensaios de tração a uma velocidade de $1 \mathrm{~mm} . \mathrm{min}-1$ até a fratura total dos corpos de prova (Figura 2A e B). No final dos ensaios, foram validados 8 corpos de prova, e os dados fornecidos pela máquina de ensaios foram organizados em planilhas de software onde realizouse os devidos cálculos que subsidiaram a elaboração de Tabelas e Gráficos que compõem o trabalho. 

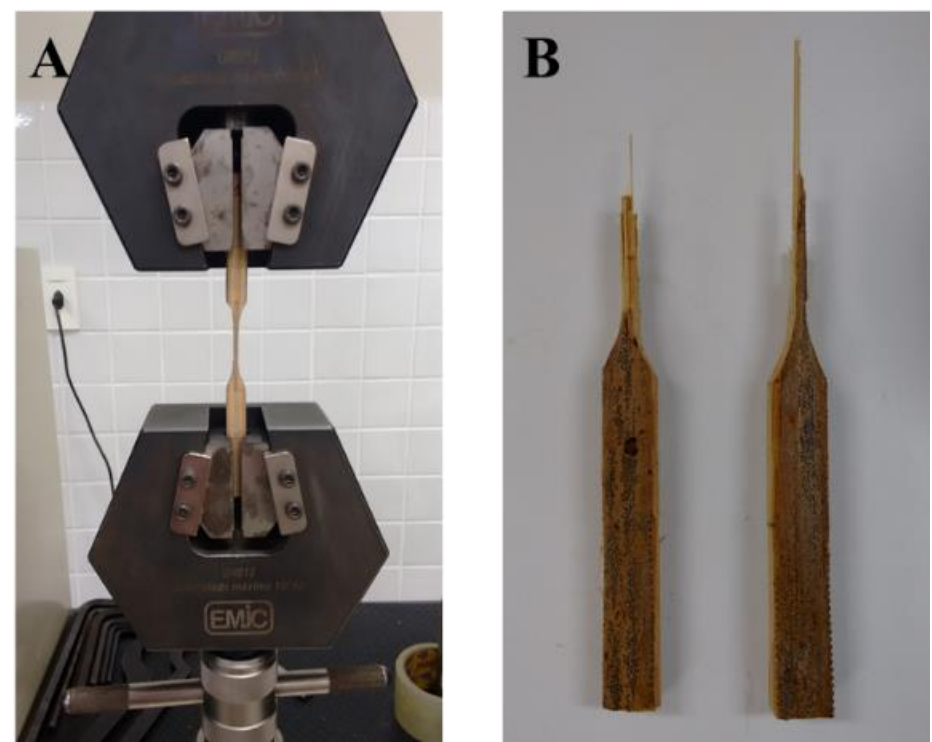

Figura 2 - Etapas de realização dos ensaios de tração. (A) Corpo de prova posicionado na máquina de ensaio universal; (B) Corpo de prova rompido após a realização do ensaio.

\section{RESULTADOS E DISCUSSÕES}

Os resultados obtidos nos ensaios de tração dos talos de carnaúba (Copernicia prunifera), apresentaram a curva de Tensão (MPa) x Deformação $\left(\mathrm{mm} \cdot \mathrm{mm}^{-1}\right)$ para cada corpo de prova validado no ensaio (Figura 3). Analisando as curvas de cada amostra, verifica-se que os talos apresentam um comportamento semelhante quando submetidos a tração, porém existe uma variação considerável em alguns valores de tensão e deformação que distanciam algumas amostras de outras, como pode ser visto na comparação dos valores de tensão de ruptura entre a curva do CP - 04 com a do CP - 07, e nos valores de deformação vistos no comportamento da curva do CP - 06 e do CP - 03 (Figura 3). O surgimento dessas variações nos valores, podem ser decorrentes de alguns fatores como os diferentes talos que foram utilizados na fabricação dos corpos de prova, tendo em vista que os talos foram coletados de várias carnaubeiras. Outro fator, está ligado ao processo de fabricação manual dos corpos de prova, que podem ter causado algum comprometimento no material, causando assim, um rompimento a uma menor tensão.

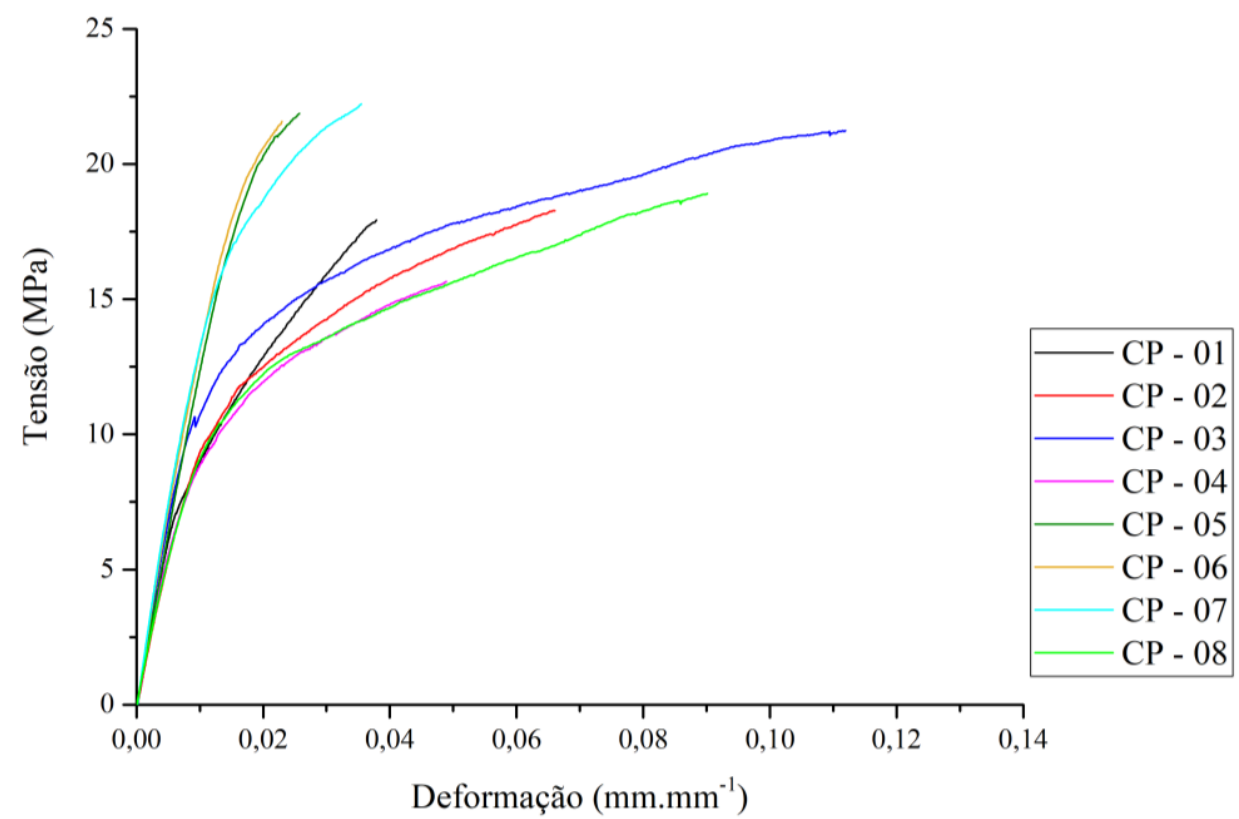

Figura 3 - Curvas de Tensão x Deformação para os 8 corpos de prova produzidos com o talo da carnaúba (Copernicia prunifera).

Apesar de existirem variações nos resultados individuais de algumas amostras, verifica-se através dos resultados médios expostos na Tabela 1, que os talos apresentam propriedades mecânicas promissoras quando submetidos à esforços de tração, orientados no sentido da fibra, apresentando um valor 
médio de resistência à tensão máxima de 19,703 \pm 2,21 MPa e uma deformação normal média de 0,0549 $\pm 0,03\left(\mathrm{~mm} \cdot \mathrm{mm}^{-1}\right)$. Essas propriedades mecânicas dos talos de carnaúba proporcionam utilidades importantes na vida de pessoas menos favorecidas, haja em vista, que segundo Lopes, Ino (2003), os talos de palmeiras como a carnaúba, são utilizadas em cidades do Nordeste brasileiro, nas construções rústicas de taipa, onde são posicionados horizontalmente na confecção do entremeado.

Tabela 1. Propriedades mecânicas do talo extraídos da carnaúba (Copernicia prunifera).

\begin{tabular}{lcccc}
\hline Propriedade Mecânica & Valor Médio & Valor máximo & Valor mínimo & Desvio Padrão (\%) \\
\hline Tensão máxima (MPa) & 19,703 & 22,212 & 15,647 & $\pm 2,21$ \\
\hline Deformação normal $\left(\mathrm{mm} . \mathrm{mm}^{-1}\right)$ & 0,0549 & 0,1119 & 0,0229 & $\pm 0,03$ \\
\hline Módulo de Elasticidade $(\mathrm{GPa})$ & 0,4858 & 0,9405 & 0,1897 & $\pm 0,27$ \\
\hline
\end{tabular}

\section{CONCLUSÕES}

A carnaúba (Copernicia prunifera) é uma arvore muito importante para a região Nordeste do Brasil, tendo em vista, que todas as suas partes, tais como a raiz, o caule, as folhas e os frutos são aproveitados e proporcionam diversos benéficos a população. Ainda que se conheça muitas de suas características e aplicações, existem partes, assim como os talos, que são muito utilizados em várias aplicações práticas, porém sem o real conhecimento das suas propriedades mecânicas. Com isso, o trabalho realizou, através de ensaios tração axial no sentido da fibra, a caracterização das propriedades mecânicas de tensão máxima média, deformação normal média e módulo de elasticidade médio para os talos, com o intuito de proporcionar uma aplicação mais segura do material. Os resultados obtidos demonstram que o talo da carnaúba apresenta considerável resistência à tração, podendo ser aplicada para diversos fins.

\section{REFERÊNCIAS BIBLIOGRÁFICAS}

ALBANO, G. P.; SÁ, A. J. DE. Vale do Açu-RN: a passagem do extrativismo da carnaúba para a monocultura de banana. Revista de Geografia, Recife, v. 26, n. 3, p. 632, 2009.
CERQUEIRA, E. B.; GOMES, J. M. A. Desmatamento da carnaúba (Copernicia prunifera (Mill.) H.E. Moore) em Campo Maior-PI. GeoTextos, Salvador, v. 13, n. 2, p. 161$182,2016$.

COMISSÃO PANAMERICANA DE NORMAS TÉCNICAS (COPANT). COPANT 30:1-015: Ensaios para madeira: tração paralela às fibras. Caracas: COPANT, 1971.

COSTA, V. L. S.; GOMES, J. M. A. Crédito e conservação ambiental no extrativismo da carnaúba (Copernicia prunifera (Mill.) H. E. Moore) no nordeste brasileiro no período de 2007 a 2012. INTERAÇÕES, Campo Grande. v. 17, n. 1, p. 4-14, 2016.

D’ALVA, O. A. Extrativismo da carnaúba no Ceará. 2004. 186 f. Dissertação (Mestrado em Desenvolvimento e Meio Ambiente) - Universidade Federal do Ceará, Fortaleza.

LOPES, W. G. R.; INO, A. Aspectos construtivos da taipa de mão. In: NEVES, C. M. M.(org). Técnicas mixtas de construcción con tierra, Salvador, BA. 2003. p. 16-36. 